\title{
History of atrial fibrillation 1628-1819 Harvey - de Senac - Laënnec
}

\author{
JOHN MCMICHAEL
}

\author{
From The Wellcome Institute for the History of Medicine, London
}

SUMMARY For two centuries after Harvey the arterial pulse was often regarded as independent of the heart beat. This misunderstanding was mainly because of the frequent failure of the irregular heart to elicit a radial pulse: the "pulse deficit" of later times.

Harvey observed ineffective palpitation of the atrium just before death. This was probably atrial fibrillation. He established the origin of the heart beat in the right atrium.

Harvey's observations were confirmed and extended by de Senac in the mid-eighteenth century. He correlated gross irregularities (palpitation) with necropsy observation of mitral valve disease and dilatation of the left ventricle. He emphasised the origin of the heart's irregularity from the distended atrium consequent on distension or reflux of blood irritating the atrial wall.

He also commented on disconcerted action and rippling of the ventricular wall before final cessation of movement in a dying heart (ventricular fibrillation).

De Senac's ideas were a century and a half ahead of his time.

\section{The problem of the pulse}

In Chapter 3 of De motu cordis (Franklin's translation, 1957) 1 are laid out the logical reasons by which Harvey comes to the conclusion:

there is just the one cause of arterial pulsation throughout the body, and that is contraction of the left ventricle. The pulsation of the artery-like vein (pulmonary artery) is similarly related to the contraction of the right ventricle . . . . In correspondence with the tension of the heart the arterial pulsations become larger, more forcible, frequent, rapid, while preserving the rhythm, volume and order of the heartbeat .... For the pulse of the arteries is nothing save the impulse of the blood entering these vessels.

This clear understanding had to wait nearly 200 years for further application in the precise study of cardiology. It was debated, and often misunderstood by practitioners of medicine, and indeed Abercromby (1685) in a book on the pulse, ${ }^{2}$ said: "Its source is as mysterious as the source of the Nile".

The belief, held by many, that arteries had an inherent movement of their own was even supported by Laënnec (1819). In discussing "intermission of the pulsation of the heart", he noted variations in the heart's contractions with or without a palpable pulse and commented as follows:

Accepted for publication 10 May 1982
Many considerations prove that the mere examination of the pulse is insufficient to inform us of the state of the circulation and must often lead us into error .... .

After what has been said and after its general uncertainty avowed by the most experienced practitioners it may seem surprising that the practice of feeling the pulse has been so generally followed in all ages. The reason for this practice is, however, sufficiently obvious. It is easy of performance and gives little inconvenience either to the physician or to the patient .... . The facts above stated relative to the discordance existing between the pulsation of the heart and of the arteries, more especially as to strength, are contrary to the more general opinion of modern physiologists who consider the action of the arteries as entirely dependent on that of the heart. Bichât himself has fallen into this error.

(Laënnec, Forbes' translation, 1821). ${ }^{3}$

Marie François Bichât (1771-1802) was the distinguished anatomist to the Hôtel Dieu, whose observations were much quoted by Laënnec. Bichât promoted the study of tissues and membranes before the era of the microscope. Thus the "pulse deficit" of atrial fibrillation seems to have contributed to the centuries long failure of the profession to accept Harvey's firm demonstration that the beating heart created the pulse. Sometimes the beat was too weak to be felt at the radial artery. 


\section{Origin of the heart beat}

Harvey's meticulous observations (chapter 4, Franklin's translation') had already established that the heart beat was initiated in the atria, and the right atrium in particular. From his many direct observations on the heart in animals, fishes, frogs, eels, birds, and domestic animals, Harvey gives the following account:

The movement is seen to begin from the auricles and to pass on to the ventricles. With everything becoming more sluggish as the heart lies dying, and also in fishes and the colder blooded animals, these two movements become separated by an interval of inactivity .... Finally as it sinks to death (the ventricle) ceases to reply with a proper movement to the pulsating auricle. The heart (i.e. ventricle) ceases to beat before the auricles so that the auricles may be said to outlive it . . . . With all the other parts inactive and dead the right auricle goes on beating so that life appears to linger longest in this auricle .... If at this time you cut the apex of the heart with a pair of scissors you will see blood flow out from the wound with each beat of the auricle. You will thus realize that the blood gets into the ventricle not through any pull exerted by the distended heart but through the driving force exerted by the beat of the auricles.

Harvey continued:

But I ... have noticed, that after the heart proper, and even the right auricle were ceasing to beat and appeared on the point of death, an obscure movement, undulation/palpitation had clearly continued in the right auricular blood itself for as long as the blood was perceptibly imbued with warmth and spirit.

Harvey must thus be credited with the first direct observation of a fibrillating atrium.

Richard Lower (1631-1691) began as research assistant to Thomas Willis and was introduced into the Royal Society by Boyle. He was the best English physiologist after Harvey and later practised medicine in London. He showed that blood changed colour to bright red in passage through the lungs and that asphyxia prevented this. He laid down in his Tractatus de Corde $(1669$, p. 75$), 4$ "The heart is definitely a muscle and has movement exactly similar to other muscles. It receives spirits from the abundance of nerves which are inserted into it".

Vital spirits from the nervous system were supposed to animate the nerves. The idea of nervous origin of the heart beat was to persist for another two centuries.

\section{De Senac's critical analysis}

In the mid eighteenth century a new dimension of analysis was added by de Senac (Fig) whose views were much in advance of his time. He built his physiological ideas on the basis of Harvey and Lower, repeating their experiments and applying critical analytical thought.

Jean-Baptiste de Senac (1693-1770), MD Montpellier, became physician to Louis XV and also became a Councillor of State. In 1749 his Traité de la Structure $d u$ Coeur de son action et de ses maladies (S) was published and a second edition appeared in $1774 . .^{5}$ This is the first textbook on cardiology. Volume I contains the most detailed account of the anatomy of the heart in adult and in fetal life and the problems of its physiology are considered thoroughly in Volume II. He also published a more concise Traité des Maladies $d u$ Coeur (M) in two editions (1774-1783). It is from the second edition and second volume of $S$ and $M$ ("structure" and "maladies") that the following extracts are made. The posthumous editions were guided through the press by Baron Antoine Portal, but the text had been revised by the author.

De Senac confirmed Harvey (S, p. 149) that in the heart of a dog dying after severing an artery, beating persists longest in the right atrium and also in the termination of the vena cava. Thus the ultimum moriens part of the heart was confirmed in the sinoatrial region.

Although de Senac built on the ideas of Richard Lower that the heart was innervated like other muscles, he asked many difficult questions: why can the heart contract after death? (S, p. 102). Cut the nerves and the heart does not stop? de Senac established irritability of the heart. Touching the heart may make it contract even more strongly. It will contract in response to internal pressure: compare the intestines. He was mystified by the visible contraction of the non-innervated embryo heart of the chick, which he thought might be the result of some still unknown agency. The debate about nervous control of the heart beat continued for another century and a half.

Just as Harvey had seen fibrillation of the atria in a dying heart, de Senac gave a description of terminal fibrillation of the ventricles (S, p. 151):

Before these parts (of the heart) lose their action the harmony of their movements is disconcerted: there is neither order nor regular succession .... When their (muscle) mass no longer makes any effort their fibres are still agitated. They form oblique ripples and there is seen, according to Pechlin, an undulation of many varieties moving from the base to the apex in a spiral form following no doubt the direction of the superficial fibres.

Johannis Nicolai Pechlin (1646-1706) observed death in an open chest wound (Historia Vulneris Thoracici, $1683^{\circ}$ ). Born in Holland, he practised in Kiel. 


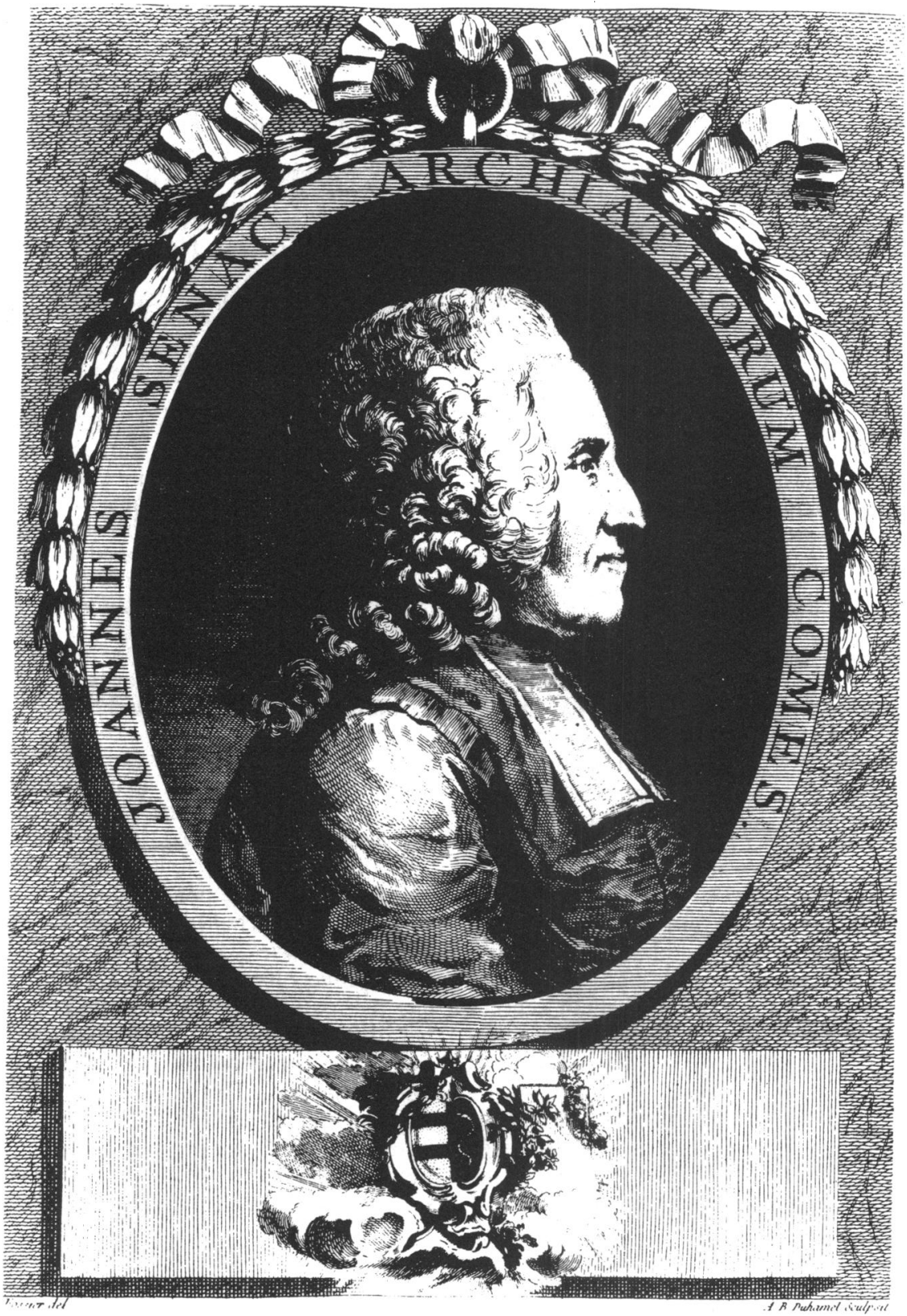

Fig Fean Baptiste de Senac (1693-1770), Courtesy of the Wellcome Trustees.

\section{Clinico-pathological correlations}

When he turned his attention to clinical abnormalities of the heart, de Senac was linking his observations with pathological anatomy in the same way as Morgagni, his slightly older contemporary.

Giovanni Battista Morgagni (1682-1771), was Pro- fessor of Theoretical Medicine at Padua from 1720 until his death. He published his book on The Seats and Causes of Diseases investigated by Anatomy in 1761. This established a pattern of observation by which the clinical manifestations of disease might be better understood.

De Senac devoted much attention to palpitation 
and his necropsy correlations are best described in his Traité des Maladies du Coeur. ${ }^{7} \mathrm{He}$ emphasised mitral valve disease in the causation of palpitation. His morbid anatomical observations are precise. Under 'The particular and proximate causes of palpitation are in the heart or in the vessels':

Cardiac causes are disorders of its very substance or of the valves. In one word obstacles which retain the blood in the ventricles and which under continuous pressure irritate the heart fibres causing stronger contractions. Reflux of blood into the auricles causes contractions of greater force, necessarily precipitating palpitations. When the obstacles in the heart obstruct the entrance to the ventricles, blood accumulates in the cavities of the auricles and irritates the fibres of their walls. Their contractions become more lively. (M, p. 7-9).

De Senac quotes a case with irregularity of the heart where the tricuspid valve was "narrowed" in the same manner as that described by Vieussens in the mitral valve (M, p. 9). He gives another description of necropsy in which "the tricuspid valve was narrowed and cartilaginous" and "the mitral valve was narrowed, stuck down to the inner surface of the ventricle and adherent to its walls. The chordae tendineae were shortened, rendering the cusps immobile" (M, p. 10). This is a precise description of a "funnel" stenosis and regurgitation of the mitral valve. Then he goes on:

Dilatation of the ventricles may also cause palpitations. This results from obstruction of the exit of blood which distends the ventricles which thus contract strongly causing more violent reflux into the auricles. (M, p. 11).

These repeated references to distension of the atria and the precipitation of contractions by pressure of the accumulating blood were somewhat prophetic of the ideas developing in the early nineteenth century when the irregular pulse of atrial fibrillation was usually regarded as a diagnostic sign of mitral stenosis, which was indeed its commonest cause. De Senac's observations had, however, also related the irregularity to enlargement of the ventricles as well. But even here he comes back to the effect of ventricular dilatation on reflux of blood into the atria.

In his discussion of palpitation in general, de Senac's remarks are full of observational clinical wisdom:

Palpitations consist of beats which are either more active and more frequent, such as occur in fever or in any action demanding effort, and even mental agitation. But these are not illnesses by themselves and do not leave any sequential damage. When the body settles down to rest the heart resumes its normal beat. (M, p. 2).

He concluded that the nerves of the heart were important in the precipitation of palpitation:

There are, however, palpitations which are lively, and irregular beats agitate the heart. The com- plaint is produced by various fortuitous events and often appearing without any obvious cause, settling down with rest, but possibly recurring. We only define as palpitations beats which are lively, irregular, agitate the heart and form a veritable malady of the beat of the heart ... continuing during rest ..... (M, p. 2).

When the palpitations are irregular they form a veritable malady of the beat of the heart acting on the great arteries. The primary cause of the disorder is an irritation ... of the tissues of the heart and a reflux of blood which is directed against the auricles with more violence . . . . The irritation is followed by contraction of the muscle and the greater the force of the ventricles the more the reflux .....(M, p. 5).

The reflux agitates the heart or disturbs its action. (M, p. 6).

If the auricles are strained and increased in volume they cause palpitations ..... On exercise too much blood arrives at the sinus of the vena cava ... its walls are irritated by the overload of blood which is driven more forcibly to the right ventricle and its action becomes more lively: hence a reflux which is still more violent and beats in response to this reflux. One sees the same effects when the auricles are abnormally dilated . . . their walls are more irritable and they act more actively on the ventricles. (M, p. 12-13).

In the case of the funnel valve described above, The ventricles send a violent reflux into the auricles. Distension of the walls of the heart makes palpitations inevitable. (M, p. 11).

In dealing with palpitation he points out that irregularities can be precipitated by distension of the stomach, which could be relieved by the use of various carminatives, and he noticed that the remedy whose effects have appeared to be the most constant and the most prompt in many cases is quinine mixed with a little rhubarb. "Long and rebellious palpitations have ceded to this febrifuge, seconded with a light purgative". This is quoted by Willius and Keys ${ }^{8}$ from his first edition of 1749 , and is prophetic of the current rational use of quinidine first observed and noted by an astute physician. De Senac's other deep insights have had little mention in medical historical texts.

De Senac's remarkable insights into the correlations of mitral disease with gross pulse irregularities were based on his own observations on cardiac muscle irritability and the atrial origin of the heart beat as established by William Harvey and expanded by de Senac's own meticulous observations. He stood firm on the atrial origin of the heart beat as established by William Harvey. Like Harvey he also put much emphasis on the development of rippling movements in the dying chambers of the heart atria and also ventricles. These are probably the earliest experimental observations of fibrillation. He commented, however 
(S, p. 52), that "the causes of palpitation are not the causes of the natural heart-beat", thereby hinting at their ectopic origin.

De Senac advanced understanding to its very limits in his day in exemplary observation and deep critical thought. He also commented on the speculative writings of others: "Rien n'est plus rare que l'exactitude d'observation" (M, p. 8).

Note: The author is responsible for the selection of quotations and translation.

The expenses of this research were defrayed by a grant from the Royal Society for the History of Science.

\section{References}

1 Harvey W. Exercitatio anatomica de motu cordis et Sanguinis in animalibus. Movement of the heart and blood in animals; translated by KJ Franklin. Oxford: Blackwell, 1957.

2 Abercromby D. De Variatione, ac Varietate Pulsus observationes. London: S Smith, 1685.

3 Laënnec RTH. De l'auscultation médiate. Paris: JA Brosson and JS Chaude, 1819. (English translation by J Forbes. London: T and G Underwood, 1821.)

4 Lower R. (1669). Tractatus de Corde. In: Gunther RT. Early science in Oxford. vol. 9. Translated by KJ Franklin. Oxford. 1932.

5 de Senac JB. Traité de la structure du coeur, de son action et de ses maladies. 2nd ed., vol. II. Paris: Mequignon l'ainé; 1783.

6 Pechlin JN. Historia Vulneris Thoracici. Kiloni J. Reumanni, Acad. Typogr, 1683.

7 de Senac JB. Traité des maladies du coeur. 2nd ed., vol. II. Paris: Méquignon l'aîné, 1783.

8 Willius FA, Keys TE. Classics of cardiology. vol. I. London: Constable, 1941.

Requests for reprints to Sir John McMichael, The Wellcome Institute for the History of Medicine, 183 Euston Road, London NW1 2BP. 